\title{
OS LIMITES DO MERCADO IMOBILIÁRIO: AS ESTRATÉGIAS E A PRODUÇÃO DO ESPAÇO NA RMG
}

\author{
THE BOUNDARIES OF THE REAL STATE MARKET: THE STRATEGIES \\ AND THE PRODUCTION OF SPACE IN RMG
}

\author{
LES LIMITES DU MARCHÉ DE L'IMMOBILIER: LES STRATÉGIES \\ ET LA PRODUCTION DE L'ESPACE DANS RMG \\ Leandro Oliveira Lima - Universidade Estadual de Goiás - Cidade de Goiás - Goiás - Brasil \\ leandro_oliveira_lima@hotmail.com
}

\begin{abstract}
Resumo
0 artigo tem por escopo analisar o processo de apropriação fundiária da Região Metropolitana de Goiânia (RMG) pelas empresas do mercado imobiliário. A análise se debruça sobre as estratégias utilizadas pelas incorporadoras e as dificuldades (não) enfrentadas pela gestão pública na regulação dos estoques de terras da RMG nas duas últimas décadas. 0 artigo contou com revisão bibliográfica e trabalhos de campo realizados durante a pesquisa de doutoramento do autor. A partir desta metodologia, discutimos os impactos socioespaciais causados pelo mercado imobiliário, que converteu mais de 60 milhões de metros quadrados em solo urbano na RMG.

Palavras-chave: mercado imobiliário, produção do espaço, RMG.
\end{abstract}

\begin{abstract}
The article aims to analyze the process of land appropriation of the Metropolitan Region of Goiania (RMG) by real estate companies. The analysis addresses the strategies used by real estate developers and difficulties (not) faced by public administration in the regulation of land inventory of RMG over the last two decades. The article includes literature review and field work carried out during the author's doctoral research. From this methodology, we discuss the socio-spatial impacts caused by the real estate market which turned over 60 million square meters into urban land in the RMG.
\end{abstract}

Key words: real estate market, production of space, RMG.

Resumé

L' article porte sur la propriété des terres de la Région Métropolitaine de Goiânia ( RMG ) par des sociétés immobilières. Analyse se concentre sur les stratégies utilisées par les promoteurs immobiliers et les difficultés (pas) rencontrées par le gouvernement dans la régulation de linventaire des terres du RMG dans les deux dernières décennies. Lsarticle comprend um examen de la littérature et de travail sur le terrain au cours de la recherche de doctorat de lsauteur. La méthode a permis de discuter des impacts socio-spatiales des développeurs de conversion de plus de 60 millions de mètres carrés de terrains urbains dans le RMG.

Mots-clés: I'immobilier, la production de l'espace, RMG.

Introdução

O debate sobre a produção do espaço torna-se primário, pois esse processo é alvo de grandes investimentos mundiais, tanto produtivos quanto financeiros. Segundo Damiani (2008), a produção do espaço faz 
parte de um processo de atualização econômica e política da metrópole, que está associado à economia mundial. $\mathrm{O}$ artigo versa sobre a problemática da produção do espaço, sobretudo aquela mais ligada à discussão acercados impactos no mercado imobiliário. Na primeira seção, apontamos os limites do mercado imobiliário, o qual é visto como ator central na produção do espaço da Região Metropolitana de Goiânia (RMG). ${ }^{1}$ Em seguida, incorremos sobre as estratégias do mercado imobiliário, no qual a ação integrada, a precificação, a especialização, a cooperação,entre outras são observadas, mais detidamente, para o caso da RMG. Por fim, nas duas últimas seções, discutimos os impactos na estrutura fundiária, que foram exemplificados a partir da experiência da RMG, além de apontarmos as (não) limitações do mercado imobiliário à produção do espaço na RMG.

\section{Os limites do mercado imobiliário}

Para demarcar os limites do mercado imobiliário, acatamos a definição aristotélica registrada em Abbagnano (2007, p. 1831), a qual se debruça sobre quatro acepções:

1) O último ponto de uma coisa, ou seja, o primeiro ponto além do qual não existe parte alguma da coisa e aquém do qual estão todas as partes dela; 2) A forma de uma grandeza ou de uma coisa que possui grandeza; 3) O término: tanto o terminus ad quem, ou ponto de chegada, quanto, por vezes, o terminus a quo, ou ponto de partida; 4) A substância ou essência substancial de uma coisa, visto ser esse o limite de conhecimento da coisa, portanto da própria coisa.

Nesse sentido, a palavra limite também significa condição, nos termos colocados por Carlos (2011). Em termos da produção do espaço, consideraremos as duas formas colocadas por Harvey (1973). Os grupos de interesses que atribuem valor de uso, e os corretores, proprietários de terras, incorporadores e indústria da construção bem como as instituições financeiras atribuem ao solo o valor de troca. O artigo focará a discussão sobre esta última forma de produção do espaço. Ademais, entre as definições apresentadas, nos interessam, diretamente, duas.

A definição no sentido de terminus a quo, ou seja, o limite do mercado financeiro como ponto de partida para a discussão da produção do espaço em ambientes metropolitanos. Definir um ponto de partida para a discussão da produção do espaço não é uma tarefa simples. Face às de- 
mandas reais, expostas em diversas cidades brasileiras, seja pelos movimentos sociais de alcance local, ou por aqueles integrados em rede-como é o caso da manifestação do Movimento dos Sem Teto, que se instalou em Aparecida de Goiânia, no final de 2014 -, discutir a importância do espaço urbano como condição vital para a sociedade, sobretudo àqueles que não possuem suas moradias, é considerar que o ponto de partida revela, em último caso, uma opção política.

Por isso, a segunda noção do termo limite, como forma de uma grandeza ou de uma coisa que possui grandeza, expressa o principal sentido que se possa atribuir ao mercado imobiliário. Tal acepção, em nosso entendimento, acaba por definir o mercado imobiliário como uma grandeza político-econômica, pois seus atores agem constantemente sobre a forma urbana, dado o seu poder de articulação sociopolítica. Com isso, definir o mercado imobiliário no início desse texto é mais do que uma tarefa metodológica, expressa uma condição inevitável da complexa forma de produção do espaço que recai sobre os ambientes metropolitanos. Além disso, essa é uma forma de expor os limites de ação do mercado imobiliário, que tem o status de ator sintagmático (Raffestin, 1993) ${ }^{2}$ na contemporaneidade face sua capilaridade de articulação, considerando as incipientes políticas territoriais e fundiárias, de um lado, e as vantagens e as facilidades de explorar a renda fundiária nos municípios, de outro lado. Em virtude destas escolhas enunciadas, entendemos que o mercado imobiliário, dado o seu poder de articulação na produção do espaço,sendo insumo dos negócios imobiliários, torna-se uma categoria fundamental para a compreensão da produção imobiliária brasileira, conforme Costa e Mendonça (2011).

Assumindo tal dimensão de importância do mercado imobiliário, é necessário explicitar algumas características (adjetivais) pelas quais ele é tratado na literatura. Por vezes, é comum encontrar a expressão empreendedores imobiliários, muito aceita e utilizada em Arquitetura, conforme Rufino (2013). A expressão mais utilizada em Geografia Urbana foi consagrada por Corrêa (2001) como agentes imobiliários. Em Sociologia, Gottdiener (1993), em sua reconhecida pesquisa sobre a produção social do espaço urbano, entende que, no conjunto da produção do espaço urbano, os atores imobiliários são os que detêm maior vantagem sobre a forma urbana, pois, agem como rede de crescimento na esteira do processo de produção do espaço.

Apesar da polissemia usada na academia e na literatura, adotamos o termo mercado imobiliário para designar o conjunto de empresas pri- 
vadas, organizadas ou não em associações, que tem como fundamento dos negócios a terra urbana como elemento central da aquisição de lucro. Ou também, como enuncia Harvey (2005), em termos de reinvestimento da produção, seja acionando e convertendo novos estoques,seja intermediando negócios com a terra urbana e a propriedade privada. Tal assertiva não pretende esgotar o conceito (e jamais conseguiríamos), mas é tomada neste texto como um limite metodológico.

Nestes termos, o mercado imobiliário é visto, em seu conjunto, como ator, dado que, nas suas particulares formas de ação, suas personalidades jurídicas reais (as imobiliárias) não escondem o interesse do poder econômico agindo sobre a produção do espaço metropolitano. Em essência, as corporações que atuam com a propriedade fundiária, em particular, ou com a produção do espaço metropolitano, em geral, mesmo estando organizadas sob um regime jurídico, possuem donos dotados de intenções políticas e econômicas muito bem definidas. Por essa razão, salienta-se que os estudos sobre a produção do espaço em ambientes metropolitanos carecem de ser tomados com delimitações metodológicas mais definidas, ou seja, que dialoguem com as categorias mercado imobiliário e propriedade privada.

Como toda grandeza possui uma forma, qual é o aspecto assumido da produção do espaço orientada pelo mercado imobiliário? No Brasil, o processo de urbanização assumiu duas formas mais sobressalentes. A primeira forma assumida, com peso considerável do mercado imobiliário, se deu na urbanização litorânea. Em forma de meio arco, dada as limitações físicas impostas pelo Atlântico, a produção do espaço mediado pelo mercado imobiliário nas cidades litorâneas esbarrou na ausência de estoques contíguos de terras. Por esse motivo, os temas da produção do espaço litorâneo contemporâneo estão pautados no processo de verticalização, conforme Dantas (2010).

No caso das cidades não limitadas pelo mar, a forma da produção do espaço assumida e acionada pelo mercado imobiliário, especialmente nas cidades planejadas, foi a radial concêntrica. Nesse caso, merece destaque Belo Horizonte, Goiânia, Brasília e Palmas. Por meio dessa disposição espacial, dada a integração dos estoques, houve maior especialização e diversificação das formas de produção do espaço pelo mercado imobiliário, em virtude: 1) da competição interna das empresas; 2) dos interesses específicos dos proprietários de glebas; 3) e, por fim, do processo histórico não aleatório de desenvolvimento do tecido urbano, por exemplo, os investimentos em infraestrutura estatal. 
Contudo, mesmo considerando estes três elementos, foram somente nas cidades com estoques fundiários concêntricos que emergiu uma forma particular de assentamento, os condomínios horizontais exclusivos de chácaras para segunda residência, os quais foram organizados pelo mercado imobiliário. No litoral, os sítios, ou espaços da vilegiaturas, originaram-se, em grande parte, por ações individuais dos proprietários de glebas, como assevera Dantas (2010).

Afirmamos que a forma dispersa e radial da metrópole permitiu um tipo integrado de ação do mercado imobiliário. Isso nos faz perceber que uma ação pontual do mercado imobiliário altera a teia de relações da produção do espaço, pois se estende em cadeia aos mais diversos pontos da metrópole. Nomeamos estratégias o conjunto destas ações, assunto discutido a seguir.

Estratégias: ação integrada, precificação, especialização e cooperação

Uma marca histórica que afeta a produção do espaço na RMG é a estratégia de correlação de forças político-partidárias vinculadas à estrutura fundiária. Entende-se esse condicionamento político como uma ação coordenada por líderes políticos com estreita relação com o mercado imobiliário. Essas ações prevalecem na contemporaneidade, como pode ser manifesta na composição do poder público municipal de Goiânia, em que o vice-prefeito (2013-2016) provém/mantém negócios no mercado imobiliário. Em virtude disso, uma ação de condicionamento político-partidário executado em Goiânia foi a não alteração da Planta de Valores Venais e a intenção de venda de áreas públicas estratégicas para o mercado imobiliário em 2014, conforme Relatório (2014).

Outro caso peculiar também é registrado em Aparecida de Goiânia. Os irmãos Tanner de Melo (ex-prefeito) e Freud de Melo (ex-candidato à prefeitura) são historicamente reconhecidos pela política de parcelamento desenfreado do território aparecidense (Pinto, 2009). Não obstante, este município se configura como o maior em percentual de lotes vagos do Brasil. O efeito do parcelamento desenfreado repercutiu de diversas formas e duas heranças desse processo são: a não ocorrência de condomínios de chácaras e a pouca expressividade de participação dos conjuntos habitacionais em Aparecida de Goiânia. A fragmentação intencional pretérita do tecido urbano aparecidense limitou as formas mais contemporâneas de uso do solo na RMG. 
Em Senador Canedo, a ascensão ao governo municipal do empresário Sr. Vanderlan Vieira Cardoso implicou em aumento da área de desafetação de terras para o setor industrial, conforme as leis n. 566/98, n. 711/01 e n. 858/02 deste município. As consecutivas obras de pavimentação e embelezamento urbano, bem como a criação do Terminal de Transporte Coletivo, da Praça Criativa e da galeria comercial fomentaram a instalação de empresas do mercado imobiliário oriundas de Goiânia, desde 2006. Tais ações implantadas no governo subsequente limitaram a intensificação da conurbação com a capital, especialmente na região da Vila Galvão, em Senador Canedo. Em outros termos, a relação político-partidária com o mercado imobiliário interfere pouco na regulação dos estoques de terras na RMG.

Em Trindade e em Goianira, apesar da relação político-partidária e do mercado imobiliário ser um caso pouco explorado, a orientação goianiense alocou excedentes demográficos e houve demanda por habitação, a partir dos conjuntos Vila Mutirão e Conjuntos Vera Cruz I e II, conforme Anjos (2009). Tal ordenamento territorial implicou um condicionamento indireto de valorização fundiária e, mais recentemente, as instalações do complexo de conjuntos habitacionais do governo do Estado, nomeados por Jardins do Cerrado, reiteraram a vinculação político-partidária e o mercado imobiliário.

A precificação é a segunda estratégia do mercado imobiliário mapeada na RMG, mas ela acomete qualquer outra cidade. ${ }^{3}$ Contudo, seus efeitos podem variar de acordo com os estoques de terras disponíveis e com as demandas por moradia. Nessa questão, mais uma vez, os ambientes metropolitanos têm vantagens em relação às demais cidades. Ainda assim, no caso das cidades planejadas, onde se desenvolveu ordenamento territorial radial concêntrico, os efeitos da precificação se tornaram ainda mais danosos.

Em 2012, segundo levantamento realizado por meio de trabalho de campo, os loteamentos com menor preço médio, registrados na RMG, ocorriam em Brazabrantes, conforme Lima (2014). O preço praticado no referido ano para um lote de $360 \mathrm{~m}^{2}$ custava 32 mil reais. Porém, já se manifestava a disposição especulativa do loteamento à medida que permitia o jogo de localização no intervalo de um conjunto habitacional popular. Fora essa exceção verificada em Brazabrantes, os lotes de tamanho padrão registravam valores e formas de financiamento similares, independente das operadoras imobiliárias. 
Ainda sobre a estratégia de precificação, observou-se que nos padrões de vendas estabelecidos entre as empresas prevaleciam o interesse nas vendas a prazo, cujos padrões de correção dos valores venais dos lotes (IGPM, inflação etc.) favoreciam uma carteira imobiliária bastante lucrativa. Sendo possível efetuar compras à vista, os valores dos lotes individuais custavam, em media, sessenta mil reais, em 2012.

Outro desdobramento do efeito da precificação registrado na RMG foi o seu caráter de extensão lateral do preço médio. Os condomínios de chácaras da RMG tiveram papel decisivo na supervalorização do solo na metrópole, como destacamos em outro momento (Lima, 2014). Um caso emblemático foi registrado em Bonfinópolis, neste município, mesmo não tendo registrado condomínio de chácara parcelado, o preço médio do metro quadrado em chácaras vendidas em varejo foi similar aos praticados em Senador Canedo e em Caldazinha. Tal fato se justifica apenas pelo que convencionamos chamar de efeito lateral da precificação e, em virtude disso, também é contado como estratégia do mercado imobiliário.

Outro fator que indicava estratégia do mercado imobiliário, e que não pode ser levado a rigor, no intercruzamento das empresas imobiliárias, foi a tendência à redução das áreas médias parceladas. Este fato se tornou comum em Senador Canedo, Trindade e Aparecida de Goiânia. Como estes três municípios dispõem de áreas parceladas mais antigas (décadas de 1970, 1980, 1990), foi prática comum entre as empresas imobiliárias desmembrar os lotes, focando as áreas mínimas de parcelamento com aprovação de financiamento via bancos públicos. Em casos de novos loteamentos, conforme verificamos em Senador Canedo, as áreas não ultrapassavam $200 \mathrm{~m}^{2}$ por unidade. Porém, face à redução das áreas, não se registrou queda no valor venal médio dos imóveis, o que repercutiu no aumento das taxas de lucros pelas empresas do mercado imobiliário.

No que se refere à especialização enquanto terceira estratégia do mercado imobiliário, verificou-se um comportamento comum que se repete em outros setores da economia capitalista. Trata-se, sobretudo, de uma decisão individual de uma empresa em focar seus negócios em segmento específico do mercado imobiliário, como identificamos anteriormente (Lima, 2014). O mercado imobiliário da RMG, em sua maioria, de empresas provenientes de Goiânia, especializou-se em diferentes seguimentos de mercado, o que, em certa medida, permitiu atenuar a competição interna por terra urbana, conforme Lima (2014). 
A disputa no mercado imobiliário é frequentemente atenuada pelos efeitos da cooperação, que será a quarta estratégia discutida. Como descreve Gottdiener (1993), tal estratégia decorre da convergência de interesses entre as empresas do segmento imobiliário. Nessa direção, destaca-se a existência da Associação das Empresas do Mercado Imobiliário (ADEMI), que se verifica em todo o Brasil e reúne uma grande parcela das empresas imobiliárias. A cooperação interna acaba por antecipar a própria lógica da metropolização. Com isso, estamos admitindo que as empresas imobiliárias ajam de forma integrada em diferentes municípios, definidas segundo plano e segmento de mercado.

Os atores imobiliários da RMG cooperam em pelo menos dois planos espaciais. O primeiro deles é o plano horizontal, que abarca desde a criação de zonas industriais, induzidas frequentemente pelo Estado, até a fabricação de unidades habitacionais simples. Este plano abrange, ainda, a produção de conjuntos habitacionais (abertos ou fechados), loteamentos simples ou fechados; a especulação imobiliária e a fragmentação de terra rural em urbana, para condomínios de chácaras de primeira ou segunda residência e sítios de recreios.

O segundo plano de expansão é o vertical. Ele não está organizado de forma muito clara em se tratando da produção e da regulação dos estoques de mercado. Estes estão frequentemente amparados por associações de representação, pesquisas de mercado, assessorias técnicas, ouvidorias, sindicatos e representantes no legislativo. Destacam-se os atores da construção civil, sobretudo aqueles ligados à produção de prédios, de escritórios, de moradia, de sobrados ou, até mesmo, aqueles que atuam no setor de luxo dos condomínios de alto padrão, como é o caso da Brookfield.

Quanto ao tipo de capital, em visita ao sítio da ADEMI-GO, em 2012, registramos pelo menos 51 empresas cadastradas. Dessas, 40 possuíam regime de capital fechado (Ltda.). ${ }^{4}$ Trata-se da maioria das empresas do ramo do setor imobiliário que tem sedes próprias localizadas em Goiânia. Dentre essas empresas de capital fechado, as principais que atuam na RMG são: Tropical Imóveis, Adão Imóveis, Rizzo, Construtora Moreira Ortence, TCI Incorporadora, Terral e Provenda Imobiliária. Das empresas de capital aberto identificamos: EMSA S/A e FGR S/A, com sede em Aparecida de Goiânia.

Os atores imobiliários têm um perfil muito diferenciado e sua escala de ação na RMG, muitas vezes, é definida em virtude do seu volume 
de capital. O destaque se dá para as empresas Tropical Imóveis, Versátil Imobiliária e Rizzo, que, embora estejam atuando no plano horizontal da produção da RMG, têm fortes vinculações com os mercados de verticalização e de aluguéis registrados em Goiânia e Aparecida de Goiânia. Isso é o que as capitaliza e o que permite a elas injetar capital no parcelamento de municípios com menor dinâmica imobiliária, como ocorre em Bonfinópolis, coma Tropical Imóveis, ou em Abadia de Goiás, com a Versátil Imobiliária, como demonstra a Figura 1.

Figura 1 - Atores imobiliários da Região Metropolitana de Goiânia, segundo segmento de mercado e municípios, 2014.
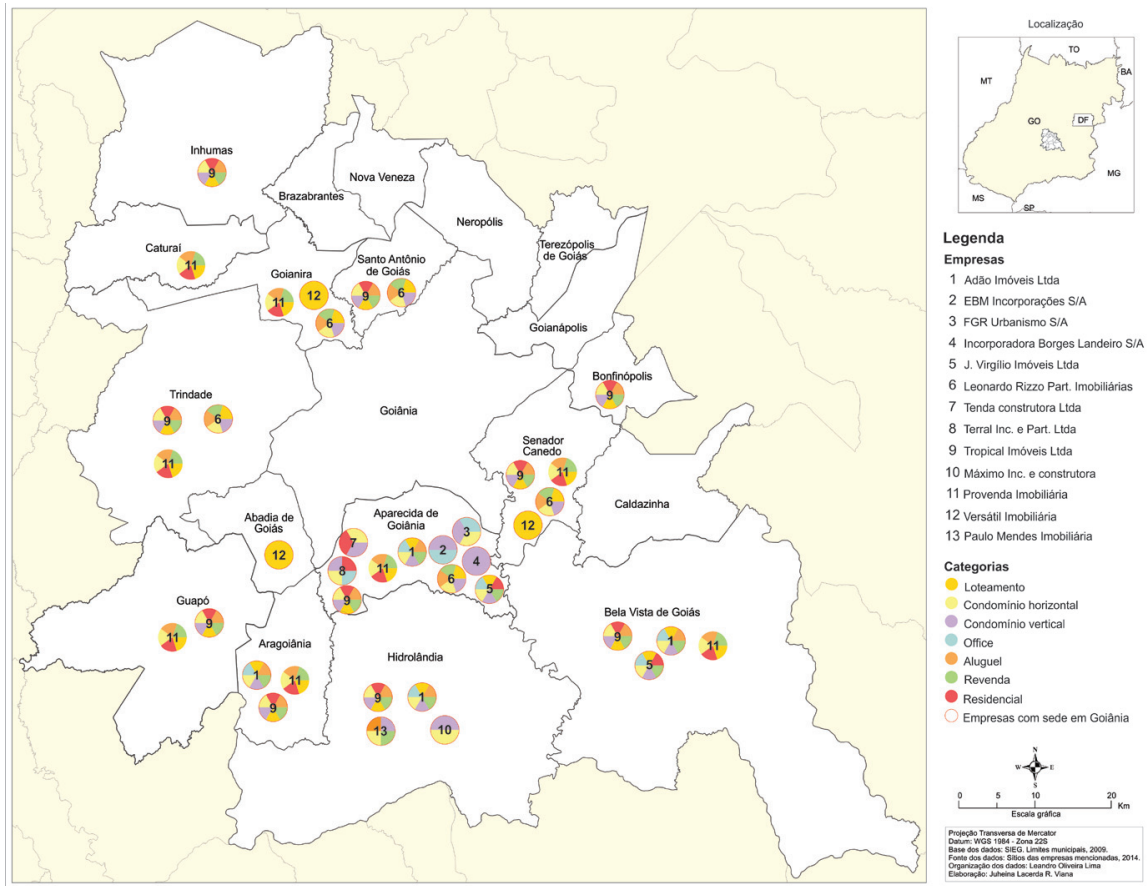

Como destaca a Figura 1, a Tropical Imóveis atuou em pelo menos seis dos 20 municípios da RMG, sobretudo naqueles onde a dinâmica do mercado imobiliário é mais intensa. Além disso, é perceptível que mais do que ter negócios nesses municípios, a empresa é responsável por dinamizar, nesses locais, o seu mercado imobiliário. Um caso notável foi a 
quantidade de lotes ofertados para a comercialização em Goianira, onde a empresa comercializava pelo menos cinco loteamentos, ofertando 4.916 lotes e comercializando, segundo os valores médios de mercado do metro quadrado do Creci (2010a, 2011), em torno de 185.942.734 milhões de reais.

Nesse sentido, para compreender as estratégias do mercado imobiliário na escala metropolitana, é necessário refletir que os atores do mercado imobiliário são mais do que um nome estampado num empreendimento imobiliário, eles detêm substancial poder de decisão tanto na escala municipal como regional, como salientou Gottdiener (1993). O conjunto das estratégias define um termo bastante conhecido no mercado imobiliário, que são as chamadas carteiras imobiliárias, conforme ilustra o Quadro 1.

Quadro 1 - Esquema Geral de Intermediação Financeira Imobiliária, RMG, 2015.

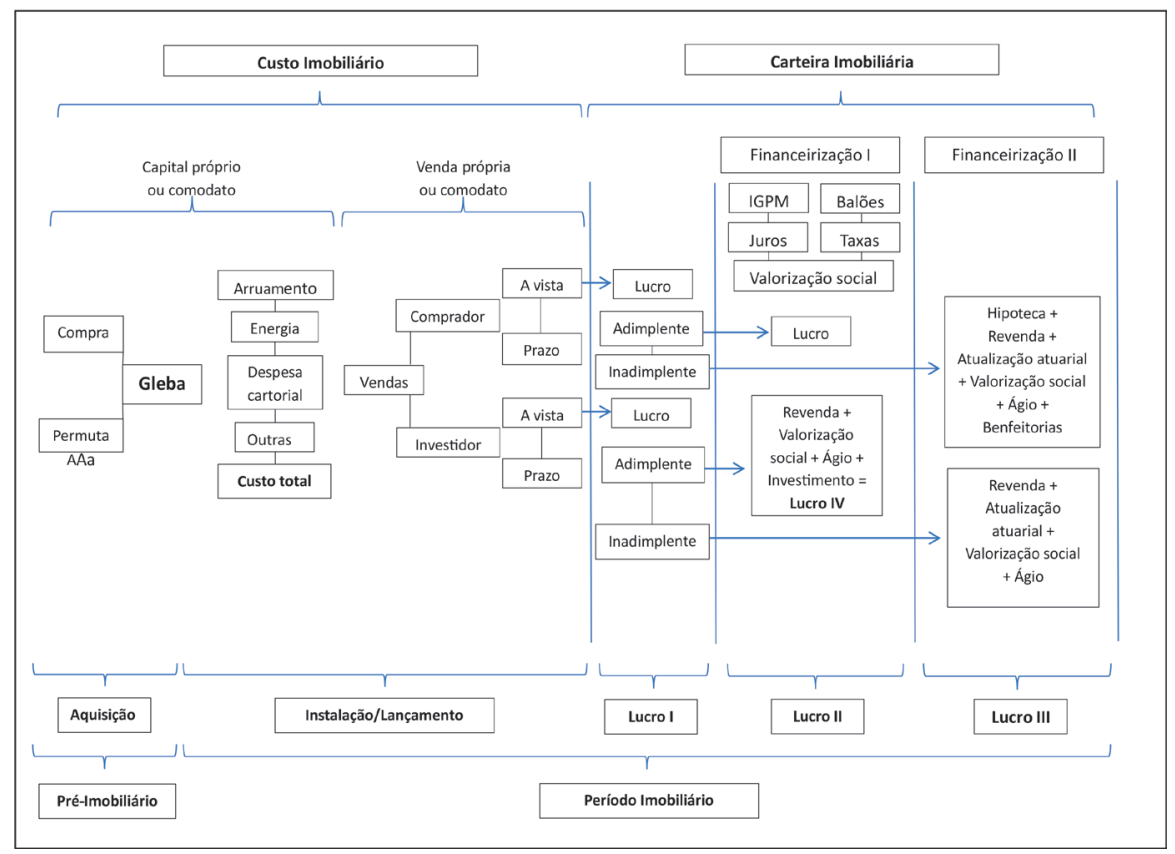

Fonte: Organizado pelo autor. 
Como elucida o Esquema Geral de Intermediação Financeira Imobiliária (Quadro 1), existem duas etapas centrais que denominamos de período imobiliário e que são comuns aos loteamentos e condomínios de chácaras da RMG. Há a fase dos custos imobiliários - compreendida entre a aquisição da gleba e a instalação e a venda -, geralmente arcados pelas próprias empresas, e a fase da carteira imobiliária - subdividida em, pelo menos, três formas de auferir lucro (lucro I, lucro II e lucro III). O lucro, indicado no esquema pelas setas azuis, perpassa todo o período imobiliário. Este, por sua vez, é o que garante estabilidade econômica às empresas, concorrência mínima entre os pares, financeirização (ações de financiamento visando maximização dos lucros), que lhes permite aumentar seus raios de ação sobre a estrutura fundiária. Assim, veremos, na seção seguinte, os efeitos espaciais do mercado imobiliário na estrutura fundiária da RMG.

\section{0 melhor negócio da terra é a renda fundiária}

O jargão que inicia a citação a seguir, trata da afirmação proferida pelo Sr. Roberto Negrão de Lima aos possíveis clientes do Condomínio de Chácaras Villa Verde em Senador Canedo. Suas palavras dão ideia da forma como um empresário do mercado imobiliário vê a terra. Em suas palavras:

O melhor negócio da terra é a terra mesmo. Esse lema orientou toda a minha experiência no Setor Negrão de Lima, que me ensinou a avaliar um bom negócio imobiliário. Desde a minha primeira visita ao VILLA VERDE, o potencial da região me ficou claríssimo: íamos inaugurar um novo acesso para a capital, que em futuro próximo estaria integrado, pelo Anel Rodoviário, a todo o entorno da Grande Goiânia. Nada melhor que investir em uma zona pioneira de valorização garantida pela beleza natural e a ligação com a área de expansão sul da cidade, onde estão preferencialmente localizados os melhores condomínios residenciais. (Lima, 2015, p. 1; grifo nosso)

Como destacamos, trata-se de uma ação cuja palavra empreender não define o impacto espacial resultante. Em virtude dos diversos interesses pautados e convergentes aos do Sr. Negrão de Lima, na RMG, ocorreu, a partir de 1999, a conversão de 35 milhões de $\mathrm{m}^{2}$ de terras rurais em condomínios de chácaras, conforme localiza a Figura 2. 
Figura 2 - Região Metropolitana de Goiânia: localização dos condomínios de chácaras selecionados, 2013.
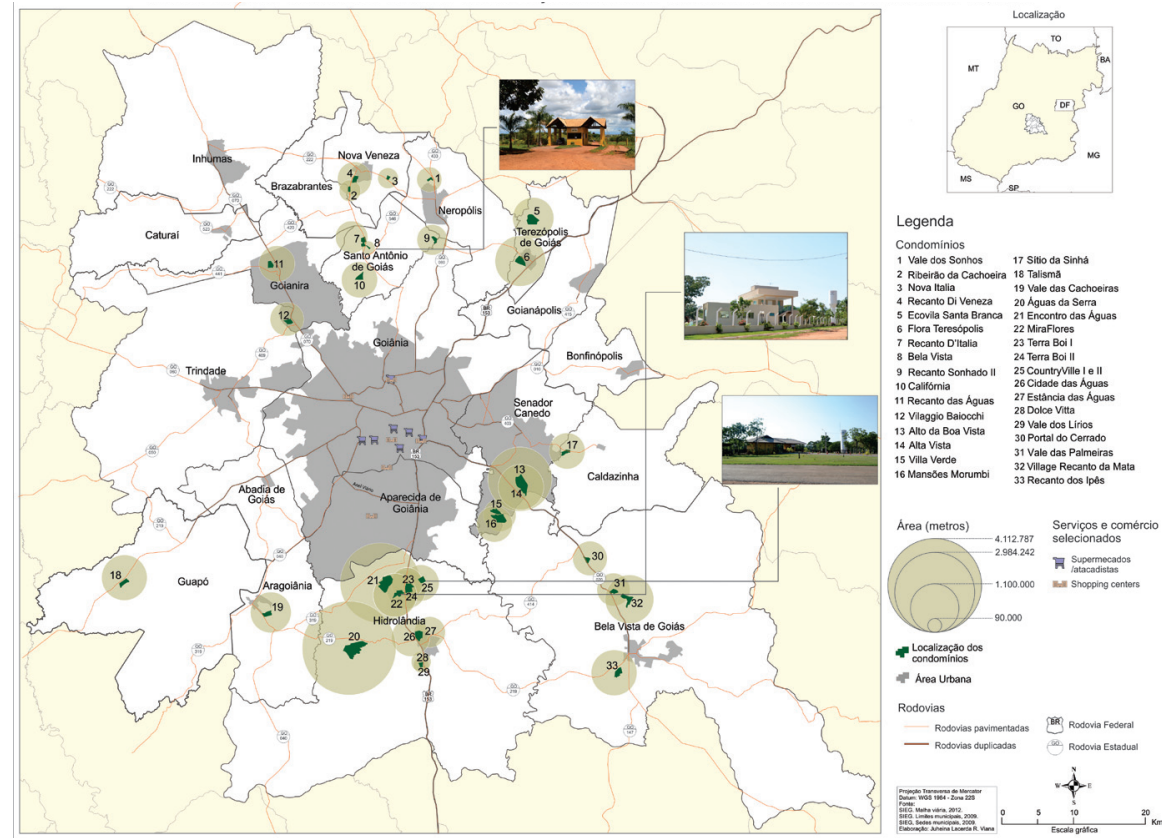

Em um total de 35 condomínios de chácaras identificados até 2013, mais de 95\% foram originados a partir dos interesses do mercado imobiliário, e não especificamente pela iniciativa do proprietário das glebas. O total de lotes ofertados nos condomínios foi de 6.989. Este fato revela a dimensão do poder de decisão do mercado imobiliário na RMG. ${ }^{5}$ Tal caminho nos permitiu compreender que as estruturas que assentam a produção do espaço não poderiam existir sem o componente fundiário integrado, do qual emana a ideia de cidade e cidadania na metrópole. Até porque, o fato de um sujeito estar situado em zona segregada, ou na periferia social, tem a ver com uma leitura integrada e globalizante da estrutura fundiária de uma metrópole.

A presença desses condomínios de chácaras na RMG foi a constatação de que é possível explorar por antecipação espacial estoques de terras em caráter especulativo. Esta ação possibilitou, via mercado imobiliário, que o metro quadrado nestes espaços fosse relativamente tão caro 
quanto o metro quadrado registrado no Complexo Alfaville, em Goiânia. Em consequência disso, houve a especulação, implantada pelo mercado imobiliário na RMG, de que 76\% do total de lotes com áreas não inferiores a $1.000 \mathrm{~m}^{2}$ estão vazios, o que viabilizou lucros iguais ou superiores aos verificados nos bairros mais valorizados de Goiânia. Em muitos condomínios de chácaras e loteamentos instalados na RMG, o custo total baixo - decorrente da aquisição da gleba, arruamento, infraestrutura e vendas - compensa as taxas de retorno elevadíssimas. A venda financiada dos lotes permite às empresas imobiliárias aplicar taxas corrigidas e executar hipotecas (IGPM, inflação, garantias contratuais etc.) de modo que um empreendimento imobiliário pode ser vendido mais de uma vez. Soma-se, ainda, o tempo de financiamento (em geral superior a 100 parcelas) mais o índice de inadimplência registrado (7,84\% em 2014, segundo a Serasa Experian).

A partir das pesquisas de valores médios do Creci (2010b; 2011), calculamos os preços aproximados do total de empreendimentos comercializados em 2012, anunciados no sítio da Tropical Imóveis. No referido ano, a empresa comercializou 15.608 unidades em toda RMG, totalizando imóveis avaliados pelos valores médios de 2010/2011 em torno de 3.696.344.049 bilhões de reais. Esse valor intermediado foi $61,44 \%$ maior que o realizado pelo governo federal em todo o estado de Goiás com os recursos do programa Minha Casa Minha Vida (MCMV), que em 2012 foi da ordem de 1.404.781.785 bilhões de reais. Esse montante coloca em questão a própria soberania do Estado como ator sintagmático, embora saibamos que as unidades ofertadas não foram executadas em sua totalidade, o que relativiza o impacto do poder econômico na produção do espaço. A área total comercializada em 2012 foi de aproximadamente 15.654.644,24 m², equivalente a 15 vezes o município de Bela Vista de Goiás, maior município em termos de área. A Tropical Imóveis ainda atua em diversos outros municípios do estado de Goiás (Iporá, Valparaíso de Goiás) e também em Mato Grosso, Maranhão e Minas Gerais.

O caso da Versátil Imobiliária também é salutar para a compreensão do poder dos atores imobiliários na RMG. A empresa divulgava em seu sítio, em janeiro de 2013, a comercialização de pelos menos 33 loteamentos, negociando (alguns já vendidos) um total de 31.258 lotes em pelo menos 12 municípios do estado de Goiás, seis na RMG e três em municípios mineiros, um no Pará e um em Tocantins. 
Na RMG, a empresa anunciava vendas de 21.091 mil unidades de lotes. Em Goiânia, a empresa vendeu, entre 2005 e 2007, 585 lotes no Residencial Araguaia. Considerando o preço médio de 2010, este loteamento custaria, pelo menos, 35.050.158 milhões de reais. Em Senador Canedo, a Versátil comercializava oito loteamentos, perfazendo um total de 6.697 mil lotes. A preço médio do metro quadrado, em 2010, segundo Creci (2010b), os lotes em Senador Canedo gerariam a receita de 183.933.105 milhões de reais. ${ }^{6}$

Em Goianira, a Versátil ofertava quatro loteamentos, os quais continham 3.546 lotes. A preço médio do metro quadrado, em 2010, segundo Creci (2010b), a empresa arrecadaria147.623.526 milhões de reais. Em Abadia de Goiás, a Versátil comercializava 5.765 lotes em 2 loteamentos. Considerando o preço médio do metro quadrado, em 2010, levantados pelo Creci (2010b), o faturamento dos lotes renderia 225.267.375 milhões de reais. Em Bela Vista de Goiás, a empresa comercializava 649 lotes, sendo 235 em loteamento fechado, na modalidade condomínio de segunda residência. Desse total, 414 lotes têm até $300 \mathrm{~m}^{2}$ e os demais custam até 85 mil reais, assim, receita estimada girava em torno de 28.213.186 milhões de reais. ${ }^{7}$

Em Trindade, a empresa detinha uma carteira estimada em 43.621.473 milhões de reais, em 2013. Na RMG, a soma total dos valores médios comercializados pela Versátil chegaria a 663.708.823 milhões de reais. Ressaltamos os valores médios da pesquisa do Creci (2011) que observou, inclusive, os preços praticados desta empresa ${ }^{8}$ Em 2012, os negócios imobiliários equivaliam a quase $50 \%$ do valor total investido pelo governo federal no programa MCMV, em Goiás, no mesmo ano.

Com base nas informações veiculadas no sítio da Paulo Mendes Imobiliária, em Fevereiro de 2013, havia pelo menos 82 unidades a serem revendidas pela empresa. Dentre essas, a maioria estava localizada em Goiânia. Havia 67 chácaras de segunda residência em Hidrolândia, sendo que 66 estavam sob o regime de lançamento do Condomínio CountryVille II. O valor total comercializado superava 11 milhões de reais em imóveis na RMG. Destaca-se que os lotes da segunda etapa do referido condomínio, em Hidrolândia, representou mais de 6 milhões de reais. 
Considerações - as (não) limitações do mercado imobiliário

De acordo com Kant, em sua Crítica à Razão Pura, o termo limitação corresponde à terceira categoria da qualidade restrição. O filósofo entendia limitação como realidade unida à negação (Abbagnano, 2007). Nas palavras colocadas por Kant, ao considerar as restrições, o termo se inverte, pois duas negativas (não limitação + restrição negativa) sobrepostas tornam-se uma afirmativa.

A despeito da problemática colocada por Garson (2009) e Souza (2008), as dificuldades enfrentadas por diferentes municípios em ambientes metropolitanos, para partilhar políticas educacionais, de saneamento ou de mobilidade, por exemplo, o mercado imobiliário não lida necessariamente com estas esferas burocráticas de poder e controle sobre a produção do espaço.

As consequências destas não limitações são assim resumidas: a) a integração dos estoques de terras nos ambientes metropolitanos à disposição dos interesses do mercado imobiliário coloca estes atores em vantagem relativa aos demais atores produtores do espaço metropolitano; b) diferentes direcionamentos das políticas governamentais à gestão territorial podem ser capitalizadores e/ou valorizadores da estrutura fundiária (caso mais emblemático é do setor de transporte coletivo; c) a ausência de um debate integrado, pelo poder público, de uma política de tributação comum sobre a propriedade fundiária, na escala metropolitana, favorece o acionamento antecipado dos estoques de terras; d) o desdobramento desta consequência é a tendência à precificação (uma espécie de cartelização do valor do metro quadrado da terra urbana) fato que nega a muitos o direito à moradia, dado o elevado preço praticado pelo mercado imobiliário; e) com efeito, a ação cooperada do mercado imobiliário torna a forma metropolitana espraiada, (convertendo mais de 60 milhões de $\mathrm{m}^{2}$ na $\mathrm{RMG}$ ) sendo que a escala espacial final da metrópole é definida pelo mercado imobiliário e não mais pela demanda real por moradia.

No caso dos compradores, prevalece a ideia de que "o investimento em imóveis é sempre atraente, e algumas indicações sugerem que ele conserve seu apelo mesmo em épocas de depressão" (Gottdiener, 1993, p. 25). Criou-se, a partir dos interesses do mercado imobiliário, um interesse secundário, em que prevalece o retorno financeiro por um grupo que compra primeiro. Nesse caso, a comercialização de ágios tornou-se 
um negócio lucrativo. Tal processo contribui para manutenção do inflacionamento do preço médio da terra urbana.

Em relação aos que compram os terrenos com a finalidade da moradia, o componente morar perto é negado, em princípio, àqueles que dispõem de parcos recursos. Com isso, a localização torna-se um fundamento unilateral, a serviço quase exclusivo do mercado imobiliário. Talvez, caso que merece estudo aprofundado, esteja nesse fato a explicação do porquê ser tão recorrente encontrar determinados sujeitos que preferem viver em moradias alugadas mais próximas do trabalho a viver distante em conjuntos habitacionais na metrópole.

Da parte dos gestores municipais, no caso da RMG, verificamos que a desatualização das plantas de valores venais bem como do processo de regulamentação dos imóveis favorecem as demandas impostas pelo mercado imobiliário. Nesse caso, é inegável a contribuição de Sposito (2011), para quem a omissão do poder público é também uma forma planejada de governo.

Sobre o novo modelo suburbano registrado na RMG, compreendemos que os condomínios de chácaras guardam forte vinculação com o modo urbano de viver. De acordo com Gottdiener (1993, p. 14) essas ocupações fazem vislumbrar o próximo estágio de um processo de "desconcentração do centro metropolitano que vem ocorrendo desde a década de 1880”, nos EUA. A novidade registrada na RMG é que tal ação é implantada involuntariamente face à demanda por espaços de lazer e segunda residência. Os condomínios de chácaras na RMG é a manifestação do poder de articulação do mercado imobiliário face à desregulamentação instalada no âmbito dos governos municipais.

Em suma, o momento atual da produção metropolitana tem mudado rapidamente em virtude da disponibilidade de capital financeiro e da sua circulação no mercado imobiliário. Tal realidade exige que novas categorias mereçam maior atenção nos estudos sobre a produção do espaço. O mercado imobiliário inventa, produz e se torna referência $a$ posteriore. Tal assertiva reitera o terceiro sentido atribuído aos limites do mercado imobiliário em que pese o terminus ad quem, ou ponto de chegada. ${ }^{9}$ 


\section{Notas}

1. A RMG é constituída por 20 municípios, que compõem o aglomerado metropolitano, definidos pela lei estadual n. 23/1998. Mais detalhes sobre a dinâmica e composição da RMG, consultar Arrais et al. (2013).

2. Nas palavras de Raffestin (1993), encontramos uma definição para o termo supracitado: "Do Estado ao indivíduo, passando por todas as organizações pequenas ou grandes, encontram-se atores sintagmáticos que produzem o território [...]. Em graus diversos, em momentos diferentes e em lugares variados somos todos atores sintagmáticos que produzem territórios" (p. 12).

3. O termo precificação é oriundo das Ciências Econômicas e da Administração de Empresas e é empregado para caracterizar as ações da atividade de venda interessada na definição dos preços de novos produtos e também do ajuste de preços para produtos já existentes. A precificação faz parte das estratégias mercadológicas e estende-se aos bens e serviços do mercado em geral. Neste artigo, usamos tal conceito para caracterizar ação similar aplicada à terra urbana, ou para captação da renda fundiária.

4. A empresa de capital fechado é aquela cujo capital é constituído por subscrição entre determinado número de sócios e cujos títulos não podem ser livremente negociados nas bolsas de valores. Disponível em:<jusbrasil.com.br $>$. Acesso em: 12 abr. 2015.

5. Para nós, só foi possível dimensionar tal ocorrência em virtude de um abandono metodológico temporário dos estudos pontuais que, até então, eram observados na Geografia goiana sobre a RMG.

6. Existem poucos loteamentos com área menor que $300 \mathrm{~m}^{2}$ naquele município.

7. Para chegar ao valor médio do $\mathrm{m}^{2}$ em Bela Vista, usamos a média das somas dos valores do $\mathrm{m}^{2}$ de Senador Canedo e Hidrolândia, já que o Creci não verificou o valor naquele município. Para contabilizar a área dos lotes, mantivemos o padrão de $300 \mathrm{~m}^{2}$.

8. Para todos os casos indicados, contando que as pessoas físicas são de fato os compradores dessas unidades habitacionais, deveríamos retirar desses valores a taxa recorde de inadimplência em 2012, que segundo o Banco Central foi de $8 \%$ em maio.

9. O artigo é resultado do projeto Capital Financeiro e Mercado Imobiliário na Região Metropolitana de Goiânia: uma análise da produção do espaço urbano a partir da renda fundiária, no âmbito da Universidade Estadual de Goiás, Campus Goiás.

\section{Referências}

ABBAGnANO, N. Dicionário de filosofia. São Paulo: Martins Fontes, 2007.

ANJOS, A. F. Dinâmica intraurbana e espaço metropolitano: um estudo sobre o município de Goianira-GO. 2009. Dissertação (Mestrado em Geografia) - Instituto de Estudos Socioambientais, Universidade Federal de Goiás, Goiânia, 2009. 
ARRAIS, T. A. et. al. Atlas das receitas públicas municipais da Região Metropolitana de Goiânia. Goiânia: Funape, IESA, 2013.

CARLOS, A. F. A. A condição espacial. São Paulo: Contexto, 2011.

CORRÊA, R. L. O espaço urbano. São Paulo: Ática, 2001.

COSTA, H. S. M.; MENDONÇA, J. G. (Orgs.). Estado e capital imobiliário: convergências atuais na produção do espaço urbano brasileiro. Belo Horizonte: Ciarte, 2011.

CRECI-GO. Pesquisa de preço: condomínios horizontais. Goiânia, 2010a.

. Pesquisa de lançamento de loteamentos residenciais do Estado de Goiás. Ğoiânia, 2010b.

. Pesquisa de lançamento de loteamentos residenciais do Estado de Goiás. Goiânia, 2011.

DAMIANI, A. M. L. A metrópole na dialética entre o território de ação estatista e o espaço de projeto político. In: CAMPOS, A.; SILVA, C. A. (Orgs.). Metrópoles em mutação: dinâmicas territoriais, relações de poder e vida coletiva. Rio de Janeiro: Revan, 2008. p. 37-53.

DANTAS, E. W. C. Antecedentes do turismo no Nordeste. In: CLEMENTINO, M. L. M.; DANTAS, E. W. C.; FERREIRA, A. L. (Coords.). Turismo e imobiliário nas metrópoles. Rio de Janeiro: Letra Capital, 2010. p. 17-34.

GARSON, S. Regiões metropolitanas: por que não cooperam? Rio de Janeiro: Letra Capital; Observatório das Metrópoles; Belo Horizonte: PUC-MG, 2009.

GOTTDIENER, M. A produção social do espaço urbano. São Paulo: Edusp, 1993.

HARVEY, D. A justiça social e a cidade. São Paulo: Hucitec, 1973.

. A produção capitalista do espaço. São Paulo: Annablume, 2005.

SENADOR CANEDO. Lei Municipal n. 566 de dezembro de 1998. Dispõe sobre a área de expansão urbana e autoriza incluir via de acesso ao Polo Coureiro como área pública em eventual loteamento, e dá outras providências. Disponível em: $<$ http://www.senadorcanedo.go.gov.br/v3/legislacao.php\#tab_10>. Acesso em: 26 jan. 2015.

. Lei Municipal n. 711 de julho de 2001. Fica considerada como Área de Expansão Industrial do Município de Senador Canedo, e dá outras providências. Disponível em: <http://www.senadorcanedo.go.gov.br/v3/legislacao. php\#tab_10>. Acesso em: 26 jan. 2015. Dispõe sobre Aprovação de loteamento Distrito Âgroindustrial, e dá outras providências. Disponível em: <http://www. senadorcanedo.go.gov.br/v3/legislacao.php\#tab_10>. Acesso em: 26 jan. 2015.

. Lei Municipal n. 858 de dezembro de 2002.

LIMA, L. O. Metropolização e mercado imobiliário: a produção do espaço dos condomínios de chácaras da RMG. Tese (Doutorado em Geografia) - Instituto de Estudos Socioambientais, Universidade Federal de Goiás, Goiânia, 2014. 
LIMA, R. N. Clipping Villa Verde. Disponível em: <http://www. condominiovillaverde.com.br/geral-condominio-cond-carta-aos-proprietarios. html>. Acesso em: 26 jan. 2015.

PINTO, J. V. C. O espaço intraurbano de Aparecida de Goiânia: centralidades na metrópole goiana. Dissertação (Mestrado em Geografia) - Instituto de Estudos Socioambientais, Universidade Federal de Goiás, Goiânia, 2009.

RAFFESTIN, C. Por uma geografia do poder. São Paulo: Ática, 1993.

RELATÓRIO. Impactos negativos da desafetação de áreas públicas no município de Goiânia-GO. Goiânia: IESA, UFG, 2014. Disponível em: <www.necropolegoiania. com.br>. Acesso em: 26 jan. 2015.

RUFINO, M. B. C. A incorporação da metrópole: algumas considerações sobre a produção imobiliária e a metropolização. In: FERREIRA, A.; MARATON, G. J.; RUA, J.; SILVA, A. C. P. (Orgs.). Metropolização do espaço: gestão territorial e relações urbano-rurais. Rio de Janeiro: Consequência, 2013. p. 131-148.

SOUZA, M. L. O desafio metropolitano: um estudo sobre a problemática socioespacial nas metrópoles brasileiras. Rio de Janeiro: Bertrand Brasil, 2008.

SPOSITO, M. E. B. A produção do espaço urbano: escalas, diferenças e desigualdades socioespaciais. In: CARLOS, A. F. A.; SOUZA, M. L.; SPOSITO, M. E. B. (Orgs.). A produção do espaço urbano: agentes e processos, escalas e desafios. São Paulo: Contexto, 2011. p. 123-145.

Leandro Oliveira Lima - Possui graduação em Geografia pela Universidade Estadual de Goiás. Mestrado em Geografia pela Universidade Federal de Goiás e Doutorado em Geografia pela mesma instituição. Atualmente é professor na Universidade Estadual de Goiás - campus da Cidade de Goiás.

Recebido para publicação em 7 de maio de 2015

Aceito para publicação em 17 de junho de 2015 